\title{
FONTES ORAIS E AS PRÁTICAS DE ALFABETIZAÇÃO NO GRUPO ESCOLAR BOM JESUS DE 1955 A 1971
}

\author{
Michelle Castro Lima \\ Instituto Federal Goiano \\ michelle.lima@ifgoiano.edu.br \\ Marco Antônio Franco Amaral \\ Instituto Federal Goiano \\ marco.amaral@ifgoiano.edu.br \\ Sônia Maria dos Santos \\ Universidade Federal de Uberlândia \\ soniam@ufu.br
}

\begin{abstract}
RESUMO
Estudar as práticas da alfabetização é ir além da análise do material didático utilizado. Este trabalho é parte de uma pesquisa que busca na memória das professoras construir a história da alfabetização, no período de 1955 a 1971, no Grupo Escolar Bom Jesus em Uberlândia -MG. Utilizamos como aporte teórico a Nova História Cultural que traz novas possibilidades de pesquisa e de fontes. Desse modo, a história oral é fundamental para a realização deste estudo, pois é a partir das vozes das próprias alfabetizadoras que construímos a história da alfabetização no Grupo Escolar Bom Jesus. Buscamos identificar quem foram essas alfabetizadoras para entender quais as representações e apropriações realizadas por elas, naquele período, e tentamos construir uma parte da história da alfabetização em Uberlândia. Os resultados revelam que as práticas são carregadas de valores e representações que essas profissionais construíram e constroem ao longo do exercício do magistério primário.
\end{abstract}

Palavras-chave: Alfabetização. Memória. História oral.

\section{ORAL SUPPLIES AND LITERACY PRACTICES IN THE BOM JESUS SCHOOL GROUP 1955 TO 1971}

\begin{abstract}
To study the practices of literacy is to go beyond the analysis of the didactic material used. This work is part of a research that searches in the memory of the teachers to build the history of literacy, from 1955 to 1971, in the Escolar Bom Jesus in Uberlândia - MG. We use as theoretical contribution the New Cultural History that brings new possibilities of research and sources. Thus, oral history is fundamental to the realization of this study, since it is from the voices of the literacy students themselves that we construct the history of literacy in the Bom Jesus School Group. We sought to identify who these literacy teachers were to understand what representations and appropriations they made in that period, and attempted to construct a part of the history of literacy in Uberlândia. The results reveal that the practices are loaded with values and representations that these professionals built and built throughout the primary teaching exercise.
\end{abstract}

Keywords: Literacy. Memory. Oral history. 


\title{
FUENTES ORALES Y LAS PRÁCTICAS DE ALFABETIZACIÓN EN EL GRUPO ESCOLAR BUEN JESÚS DE 1955 A 1971 RESUMEN
}

Estudiar las prácticas de alfabetización es ir más allá del análisis del material didáctico utilizado. Este trabajo es parte de una investigación que busca en la memoria de las profesoras construir la historia de la alfabetización, en el período de 1955 a 1971, en el Grupo Escolar Bom Jesús en Uberlândia -MG. Utilizamos como aporte teórico la Nueva Historia Cultural que trae nuevas posibilidades de investigación y de fuentes. De este modo, la historia oral es fundamental para la realización de este estudio, pues es a partir de las voces de las propias alfabetizadoras que construimos la historia de la alfabetización en el Grupo Escolar Bom Jesús. Buscamos identificar quiénes fueron esas alfabetizadoras para entender qué representaciones y apropiaciones realizadas por ellas, en aquel período, e intentamos construir una parte de la historia de la alfabetización en Uberlândia. Los resultados revelan que las prácticas se cargan de valores y representaciones que estos profesionales construyeron y construyen a lo largo del ejercicio del magisterio primario.

Palabras clave: Alfabetización. La memoria. Historia oral

\section{SOURCES ORALES ET PRATIQUES D'ALPHABÉTISATION AU SEIN DU GROUPE SCOLAIRE BOM JESUS DE 1955 À 1971}

\begin{abstract}
RÉSUMÉ
Étudier les pratiques d'alphabétisation, c'est aller au-delà de l'analyse du matériel didactique utilisé. Ce travail fait partie d'une recherche qui cherche dans la mémoire des enseignants à construire l'histoire de l'alphabétisation, de 1955 à 1971, dans l'Escolar Bom Jesus à Uberlândia - MG. Nous utilisons comme contribution théorique la nouvelle histoire culturelle qui apporte de nouvelles possibilités de recherche et de sources. Ainsi, l'histoire orale est fondamentale pour la réalisation de cette étude, puisque c'est à partir des voix des étudiants en alphabétisation elles-mêmes que nous construisons l'histoire de l'alphabétisation dans le groupe scolaire Bom Jesus. Nous avons cherché à identifier ces alphabétiseurs qui devaient comprendre quelles représentations et quelles appropriations ils avaient faites pendant cette période, et nous avons tenté de construire une partie de l'histoire de l'alphabétisation en Uberlândia. Les résultats révèlent que les pratiques sont chargées de valeurs et de représentations que ces professionnels ont construites et construites tout au long de l'exercice d'enseignement primaire.
\end{abstract}

Mots-clés: Alphabétisation. Mémoire. Histoire orale.

\section{INTRODUÇÃO}

Com a crescente discussão sobre as práticas na alfabetização, observamos a necessidade de realizar uma reflexão sobre a importância das fontes orais para a produção da História da Alfabetização nos últimos 15 anos. Temos privilegiado, em nossas pesquisas, as fontes orais como opção metodológica, pois percebemos que as pesquisas sobre história da alfabetização foram construídas ao longo dos últimos estudos a partir dos documentos oficiais e 
bibliográficos. Escolhemos articular, como baliza teórica, a História Cultural, pois ela "tem como principal objeto identificar o modo como em diferentes lugares e momentos uma determinada realidade é dada a ler" (CHARTIER, 2002, p. 61). De acordo com Chartier (2002), na História Cultural, é importante considerar "o consumo cultural ou intelectual como uma produção, que constitui representações nunca idênticas às que o produtor, o autor, ou o artista investiram na sua obra" (CHARTIER, 2002, p. 61). Destarte, não existem objetos históricos fora de suas práticas nem discursos e realidades definidas, fixas em cada situação histórica. Assim, a relação do texto com o real é construída segundo modelos discursivos e delimitações intelectuais, próprios de cada situação escrita.

\section{HISTÓRIA CULTURAL E AS POSSIBILIDADES METODOLÓGICAS}

A publicação da revista Annales d'histoire économique et sociale, em outubro de 1929, expressou uma nova tendência da historiografia francesa, erguendo-se contra a dominação da Escola Positivista. As ideias e ideais da revista apontam outras formas de pesquisa que consideravam diferentes fontes, aproximando, assim, a História das outras ciências humanas.

Ao propor que o homem fosse apreendido em sua totalidade, a Escola dos Annales aponta aos historiadores novas possibilidades para o desenvolvimento das pesquisas, ampliando o campo de trabalho do historiador em relação aos atores e aos temas, e a seus objetivos. Assim, é necessária uma História aberta às ciências humanas, conforme afirmaram Bourdé e Martin (2018):

\footnotetext{
Erguendo-se contra a dominação da Escola Positivista, uma nova tendência da historiografia francesa exprime-se bastante discretamente em 'A Revista de Síntese' durante os anos 1920, mais francamente na 'Revista Les Annales' durante os anos 1930. A corrente inovadora (Annales) despreza o acontecimento e insiste na "longa duração"; deriva a sua atenção da vida política para a atividade econômica, a organização social e a psicologia coletiva. (BOURDÉ; MARTIN, 2018, p. 119).
}

Segundo um dos idealizadores desse movimento, Lucien Febvre, a História não deve ser o registro da sequência de acontecimentos que parte apenas dos documentos escritos, mas deve se utilizar de documentos não escritos e fazer apelo a outras ciências, abordando todos os aspectos da atividade humana. Assim, “[...] stock de documentos de que a história dispõe não é limitado; sugere não utilizar exclusivamente documentos escritos e recorrer a outros materiais [...]” (BOURDÉ; MARTIN, 2018, p. 125).

Até 1968, Fernand Braudel dirigiu a Revista dos Annalles de forma incontestável e, a 
partir daquele ano, formou um comitê para auxiliar na publicação e direção da revista. Esse comitê era formado por intelectuais como Jacques Le Goff, E. Le Roy Ladurie e M. Ferro. Com essa nova direção, novos problemas e novos objetos começaram a emergir, e esboçaram-se novas abordagens, explicitadas na enciclopédia intitulada A Nova História, dirigida por Le Goff, em 1978.

A partir da publicação da coleção de ensaios, editada por Le Goff, a expressão Nova História ficou conhecida. Dessa forma, enquanto a Escola dos Annales interessava-se pela Europa Ocidental e por suas dependências, a Nova História procurou compreender os grandes espaços e as grandes massas históricas. Ao contrário do Positivismo, ela revela outras possibilidades de fontes para as pesquisas.

A Nova História tem como um de seus pressupostos a compreensão de que a realidade é social e culturalmente construída e, por isso, o pesquisador deve se preocupar com a análise das estruturas, abrindo-se para novos objetos de pesquisa e, por consequência, buscar novas fontes para suplementar os documentos oficiais como a fonte oral, as evidências das fontes iconográficas e as estatísticas.

Nesse contexto, a história deixa de ser historicizante para se tornar uma história problematizadora do social, preocupada com as massas anônimas, seus modos de viver, sentir e pensar. Nessa direção, foram excluídas as concepções de viés marxista, que entendiam a Cultura como integrante da superestrutura, como mero fluxo da infraestrutura, ou mesmo da Cultura como manifestação superior do espírito humano e, portanto, domínio das elites. A Nova História propõe um olhar cuidadoso sobre a Cultura. Segundo Pesavento (2012, p. 15), "não mais como uma mera história do pensamento, onde estudavam-se os grandes nomes de uma dada corrente ou escola. Mas, enxergar a cultura como um conjunto de significados partilhados e construídos pelos homens para explicar o mundo".

Dentro dessa nova ótica historiográfica, focamos nossas pesquisas e estudos em auxiliar a difícil construção da história da alfabetização no Brasil, a partir das práticas e métodos pedagógicos utilizados pelas alfabetizadoras, mais especificamente àqueles voltados à leitura e escrita. Acreditando que a História é a "Ciência dos Homens" e "dos Homens, no tempo", como afirma Bloch (2002, p. 55), aprendemos, ao longo de nossa trajetória, que não devemos transportar ingenuamente o presente para o passado, muito menos procurar um trajeto linear que seria tão ilusório como o sentido contrário.

Neste contexto, uma questão emerge: o que é representação? Para responder, é necessário marcar cronologicamente as reflexões que pontuam a vida de uma cultura, buscando a herança que cada alfabetizadora (sujeito de nossos estudos e pesquisas) recolhe do passado, 
já que "representar é [...] fundamental, estar no lugar de, é presentificação de um ausente; é um apresentar de novo, que dá a ver uma ausência. A ideia central é, pois, a da substituição, que recoloca uma ausência e torna sensível uma presença” (PESAVENTO, 2012, p. 40).

O objetivo central da representação é trazer para o presente o ausente vivido e, dessa forma, poder interpretá-lo. Nesta mesma perspectiva, compreendemos que o cerne da apropriação é "construir uma história social das interpretações, remetidas para suas determinações fundamentais" (CHARTIER, 1990, p. 26), que são o social, o institucional e, sobretudo, o cultural. Dessa forma, o passado só chega aos dias atuais por meio das representações, dos mitos, emblemas e sinais: "A rigor, o historiador [da cultura] lida com uma temporalidade escoada, com o não visto, o não vivido, que só se torna possível acessar através de registros e sinais do passado que chegam até ele" (PESAVENTO, 2012, p. 42).

Como afirma Chartier (1990),

As representações do mundo social assim construídas, embora aspirem à universalidade de um diagnóstico fundado na razão, são sempre determinadas pelos interesses de grupo que as forjam. Daí, para cada caso, o necessário relacionamento dos discursos proferidos com a posição de quem os utiliza. (CHARTIER, 1990, p. 17).

Um dos principais aspectos da cultura que se constitui objeto de ensino na escola é precisamente a linguagem/língua, que nos precede, ultrapassa, institui e constitui como seres humanos e sujeitos sócio-históricos. Podemos considerar que a publicação da revista Annales d'histoire économique et sociale descerrou a possibilidade para as pesquisas sobre história da alfabetização, já que proporcionou diferentes visões para a pesquisa historiográfica.

Mediante as novas possibilidades de pesquisa advindas da Escola dos Annales, e por se tratar de uma análise qualitativa, temos utilizado, nos últimos quinze anos, em nossas pesquisas, de fontes orais; assim, nos apropriamos das narrativas das alfabetizadoras, colhidas por meio de entrevistas individuais. A cultura escolar muito nos interessa como uma dimensão da história cultural, pensando a Cultura como um modo de vida e tendo, como parâmetro, o conceito de cultura escolar elaborado por Julia (2001):

É necessário, justamente, que eu me esforce em definir o que entendo aqui por cultura escolar; tanto isso é verdade que esta cultura escolar não pode ser estudada sem a análise precisa das relações conflituosas ou pacíficas que ela mantém, a cada período de sua história, com o conjunto das culturas que lhes são contemporâneas: cultura religiosa, cultura política ou cultura popular. Para ser breve, poder-se-ia descrever a cultura escolar como um conjunto de normas que definem conhecimentos a ensinar e condutas a inculcar, e um conjunto de práticas que permitem a transmissão desses conhecimentos e a incorporação desses comportamentos; normas e práticas 
coordenadas a finalidades que podem variar segundo as épocas (finalidades religiosas, sociopolíticas ou simplesmente de socialização). Normas e práticas não podem ser analisadas sem se levar em conta o corpo profissional dos agentes que são chamados a obedecer a essas ordens e, portanto, a utilizar dispositivos pedagógicos encarregados de facilitar sua aplicação, a saber, os professores primários e os demais professores. (JULIA, 2001, p. 10-11).

Nossos estudos buscam evidenciar indícios para que possamos compreender e dar visibilidade ao processo que ocorreu no espaço escolar, por meio das práticas das alfabetizadoras brasileiras. Ainda que a documentação fosse escassa ou estivesse danificada, foi possível reconstruir diferentes representações culturais, a partir de sinais oferecidos por essas fontes, indicadores da relação da entidade escolar com a sociedade, do professor com o aluno e suas contribuições para a formação da cultura escolar.

Nessa perspectiva, o método do paradigma indiciário ${ }^{1}$ tem contribuído para nossas pesquisas, uma vez que seu apego ao detalhe revelador não deixa de estabelecer o diálogo entre a parte e o todo, salvaguardando o pesquisador de cair na armadilha da descrição positivista, ingênua e romântica.

\section{FONTE ORAL: POSSIBILIDADES METODOLÓGICAS}

No contexto atual, é fundamental reconhecer a importância de estudos relacionados às tradições culturais. A oralidade é o elemento essencial para a caracterização e consolidação dessa fonte, também conhecida como História Oral, que está presente em nossas vidas e tem grande importância para a pesquisa. Thompson (1998) enumera diversos exemplos de história oral que caracterizam as comunidades e os indivíduos e demonstra como a História Oral, utilizada para transmitir suas atitudes e concepções, é um artifício para estudos relacionados à vida de grupos, comunidades ou pessoas.

A História Oral valoriza a memória do homem, mas não pode ser definida cronologicamente. No momento da entrevista, o pesquisador/entrevistador deve estar atento às respostas, pois as lembranças não são cronológicas. Elas vão e vêm, por isso devemos lapidar as narrativas, pois elas são vivências e experiências.

A memória é essencial para o desenvolvimento de uma pesquisa que tenha como método a História Oral. Para Delgado (2006), recorremos à memória como aporte fundamental que

\footnotetext{
${ }^{1}$ Para mais informações, consultar: GINZBURG, Carlo. Mitos, Emblemas e Sinais: morfologia e história. São Paulo: Cia das Letras, 1989.
} 
subsidia e alimenta as narrativas que constituirão o documento final, a fonte histórica produzida. Em nossos estudos, tem sido imprescindível refletir sobre a memória, lembrando-nos que, para conceber o problema da recordação e da localização das lembranças, é importante tomar como ponto de referência os contextos sociais reais que serviram de baliza para a reconstrução da memória.

As cenas podem ou não deixar traços. Para Halbwachs (2006), temos duas memórias: a individual e a coletiva. A individual está interligada à coletiva, já que, em sua maioria, a memória individual foi vivenciada em um grupo que pode auxiliar na sua reconstrução. Porém, para que ela se aproveite dos testemunhos dos outros, é necessário que tenham ocorrido pontos de contato de nossas memórias.

Podemos dizer que a memória individual não é intrínseca (interna) à memória coletiva. A individual é a lembrança dos nossos sentimentos no momento da cena. Assim, todos podem se lembrar da cena, porém somente quem a vivenciou poderá dizer o que sentiu naquele momento. Contudo, para relembrar esse sentimento, por vezes, é necessário que alguém do grupo fale, a relembre, para que o sentimento retorne. A memória individual é um ponto de vista da coletiva, "assim, na base de qualquer lembrança haveria o chamamento a um estado de consciência puramente individual que chamamos de intuição sensível - para distingui-lo das percepções em que entram alguns elementos do pensamento social" (HALBWACHS, 2006, p. 42).

Nossas lembranças estão sempre ligadas a uma base social, misturadas a imagens, com pensamentos ligados a outras pessoas e aos grupos que nos rodeiam. Por isso, não nos lembramos da nossa primeira infância, porque nossas impressões não se ligam a nenhuma base social. Sendo assim, nossa memória não se apoia na história aprendida, mas sim na história vivida.

A lembrança corresponde a um acontecimento distante no tempo, a um momento de nosso passado: “é o que Bergson chama de reconhecimento em imagem, ou a sensação do déjà $v u$ " (HALBWACHS, 2006, p. 55); ademais,

\footnotetext{
Quando dizemos que a recordação de certas lembranças não depende da nossa vontade, é porque a nossa vontade não é forte o suficiente. A lembrança está ali, fora de nós, talvez dispersa entre muitos ambientes. Se a reconhecemos são as forças que a fizeram reaparecer e com as quais sempre mantivemos contato. (HALBWACHS, 2006, p. 59).
}

Nesse sentido, pode-se recorrer às lembranças de outros e se transportar a referências externas determinadas pela sociedade. Para o funcionamento da memória individual, é 
importante a utilização de instrumentos tomados do ambiente, já que nossa memória está interligada ao grupo social ao qual pertencemos. Ela se liga ao tempo e ao espaço do grupo social:

\footnotetext{
Assim, não há memória coletiva que não aconteça em um contexto espacial. Ora, o espaço é uma realidade que dura: nossas impressões se sucedem umas às outras, nada permanece em nosso espírito e não compreenderíamos que seja possível retomar o passado se ele não estivesse conservado no ambiente material que nos circunda. (HALBWACHS, 2006, p. 170).
}

Como nossa memória sempre está interligada à memória do grupo, esse passado nunca é individual, mas de um indivíduo inserido num contexto familiar, social, nacional. Diante dessas colocações, verificamos que a memória é de suma importância para se desvelar a História das Práticas de Alfabetização.

As representações das alfabetizadoras são reveladas nas suas narrativas. São depoimentos nos quais elas contam como foi o seu processo de alfabetização e de formação, falam acerca dos alunos que frequentaram suas turmas e da estrutura física e política do lugar em que atuaram. Essas narrativas trazem as marcas do coletivo social que as envolve. Sendo assim, toda história está impregnada de vivências sociais, o que nos auxilia a compreender o processo de alfabetização no período estudado, já que

\footnotetext{
Memória, história: longe de serem sinônimos, tomamos consciência de que tudo opõe uma à outra. A memória é vida, sempre carregada por grupos vivos e, nesse sentido, ela está em permanente evolução, aberta à dialética da lembrança e do esquecimento, inconsciente de suas deformações sucessivas, vulnerável a todos os usos e manipulações, susceptível de longas latências e de repentinas revitalizações. A história é a construção sempre problemática e incompleta do que não existe mais. A memória é um fenômeno sempre atual, um elo vivido no eterno presente; a história, uma representação do passado. Porque é afetiva e mágica, a memória não se acomoda a detalhes que a confortam; ela se alimenta de lembranças vagas, telescópicas, globais ou flutuantes, particulares ou simbólicas, sensível a todas as transferências, cenas, censura ou projeções. A história, porque operação intelectual e laicizante, demanda análise e discurso crítico. A memória instala a lembrança no sagrado, a história a liberta, e a torna sempre prosaica. (NORA, 1981, p. 9).
}

Ao construirmos uma História das práticas das alfabetizadoras, é importante compreender o papel e a importância da memória como possibilidade de revelar as histórias a partir das entrevistas. As narrativas podem trazer contribuições significativas à pesquisa, na medida em que podem revelar fatos pessoais que, em sua maioria, não foram documentados.

As histórias orais narradas têm um valor extraordinário e, por isso, não devem ser reduzidas a um mero documento adicional, já que toda história precisa de sua finalidade social. 
Assim, os fatos coletivos ficam evidentes com a história oral, pois, com o seu auxílio, podemos cruzar os depoimentos de várias pessoas de diferentes camadas sociais, envolvidas nas vivências e experiências, bem como cruzar os depoimentos com a fonte documental, iconográfica ou bibliográfica.

A partir do início do século XX, os relatos orais vão, gradativamente, assumindo o patamar de fontes, contando com a contribuição das concepções advindas da Nova História. Segundo Thompson (1998), muitas vezes, quando uma pessoa é entrevistada, ela percebe a relevância de sua perspectiva, o que é capaz de despertar forças; de igual modo, a recuperação de lembranças acaba promovendo sentimentos que podem renovar suas vidas.

Utilizar a fonte oral nos estudos é uma das formas de valorizar quem vivenciou determinados contextos e pode nos relatar detalhes que, provavelmente, nunca seriam escritos nos documentos oficiais. Thompson expõe, em a Voz do Passado (1998), o quanto perdemos ao acreditar que apenas o que está escrito é verdade; pois toda história depende basicamente de sua finalidade social e os fatos coletivos ficam mais evidentes com a História Oral. Através dela podemos cruzar depoimentos de várias pessoas de diversas camadas sociais envolvidas nos fatos e preencher lacunas existentes (pois a escolha das fontes também é uma seleção que o pesquisador faz).

Na nova perspectiva historiográfica, a história oral pode ser concebida como um método e, nessa condição, as entrevistas são consideradas como fundamento da investigação. Elas são um instrumento que recorre à vida das pessoas. A História Oral oferece recursos para que o objetivo de uma dada pesquisa possa ser alcançado, envolvendo um conjunto de procedimentos que se iniciam na seleção das pessoas a serem entrevistadas, seguem com a elaboração das perguntas a serem feitas, realização de entrevistas, transcrição dos depoimentos e, por último, a sua análise de acordo com o objetivo do estudo (as entrevistas são transcritas e aprovadas pelos seus autores) (MEIHY; HOLANDA, 2007). É válido ressaltar, ainda, uma característica do entrevistador que nem sempre é mencionada em meio aos demais critérios e requer atenção: trata-se da aquisição de sensibilidade para as palavras, o que pode resultar num encontro precioso.

A História Oral tem a função de registrar as experiências humanas, pois se constrói em torno das pessoas, de modo que tanto o pesquisador como o narrador constroem sabedoria ao ouvir e ao narrar as histórias.

As narrativas colhidas não são consideradas dados complementares a outras fontes de informação, mas possuem valores próprios; são fontes fidedignas de testemunhos subjetivos, falados. Portanto, o gravador é essencial para a realização das entrevistas, já que as gravações 
não editadas possuem linearmente a história como realmente foi dita: é a história contada por quem a vivenciou.

Apesar da aparente facilidade, antes da construção do texto e de suas análises, existe um trabalho árduo, que antecede as entrevistas. É necessário ter claro o problema de pesquisa, estruturar o roteiro das entrevistas, realizar inúmeras conversas, antes da gravação, para que o entrevistado se sinta seguro e desejoso de responder. Além disso, o lugar onde realizamos as entrevistas tem de ser escolhido com cuidado, pois deve ser calmo, aconchegante e iluminado, ou seja, um lugar onde se possa conversar com tranquilidade. O dia e o horário também são importantes, pois as alfabetizadoras a serem entrevistadas devem se sentir acolhidas, desejando ser entrevistadas e terem tempo para poder lembrar de detalhes que, na pressa, podem ser ignorados.

Como pesquisadoras, construímos um caderno de anotações para "colaborar com a hipótese do levantamento, preencher as lacunas do formulário" (THOMPSON, 1998, p.148). Além disso, é necessário que haja respeito mútuo (entrevistador/entrevistado) e cuidado com a quantidade de perguntas, lembrando sempre que existe diferença entre entrevistas realizadas com jovens e idosos, professores e alunos. Lidamos com pessoas maduras, profissionais mais velhos que estão interessados em dividir suas experiências, frustrações, amores e dissabores da profissão, que desejam narrar suas vivências e experiência não documentadas, e muitas delas se consideram exemplo de um tempo. O saber docente é histórico e precisa ser registrado. Portanto, as histórias narradas pelas alfabetizadoras revelaram processos por meio dos quais, ao longo dos anos, elas construíram seus conhecimentos e suas práticas.

Até o final do século XIX, os historiadores davam prioridade aos registros escritos, especialmente os considerados oficiais, e as informações orais não eram julgadas como fontes históricas. De acordo com Meihy (2013, p. 42),

\footnotetext{
O domínio da palavra escrita sobre a oral sempre existiu e desde o princípio impôs uma guerra entre os dois códigos. Já nos registros das sociedades antigas, começando pelos egípcios com os chamados escribas, a palavra escrita passou a ganhar valor em detrimento da oral, que passava a ser recurso vulgar e território da comunicação comum e da transmissão da memória.
}

Neste contexto, não se questionava a oficialidade dos documentos, porém se criticava a fidedignidade da história oral, o que só começou a se modificar com a criação da Escola dos Analles. Nesse contexto, a pesquisa com a Metodologia de História Oral abarca todo um processo de atividades prévias e subsequentes às gravações. 


\section{AS ENTREVISTAS: REGISTRO DAS VOZES DOS NARRADORES}

Na perspectiva historiográfica, a História Oral é concebida como um método e, nesta posição, as entrevistas são consideradas como fundamento da investigação.

Thompson (1998) pondera que

Há algumas qualidades essenciais que o entrevistador bem-sucedido deve possuir: interesse e respeito pelos outros, como pessoas, e flexibilidade nas reações em relação a eles; capacidade de demonstrar compreensão e simpatia pela opinião deles: e, acima de tudo, disposição para ficar calado e escutar. (THOMPSON, 1998, p. 254).

A entrevista é um processo muito importante, no qual deve se tomar um cuidado especial com as perguntas. Thompson (1998) propõem alguns princípios para ser pensado durante a preparação das perguntas: “As perguntas devem ser sempre tão simples e diretas quanto possível, em linguagem comum. Nunca faça perguntas complexas ou de duplo sentido [...] evite induzir a uma resposta... E sempre que possível evite interromper uma narrativa [...]" (THOMPSON, 1998, p. 260-263).

Outro fator importante é o local onde a entrevista está sendo realizada, pois o mesmo pode alterar o resultado da entrevista, modificando o discurso do entrevistado, por este motivo faz-se necessário que a entrevista ocorra em um local no qual o entrevistado se sinta aconchegado.

De acordo com Meihy (2013), a entrevista passa por três procedimentos, que são transcrição, textualização e transcriação, estas etapas segundo a autor referem a:

1. Transcrição: processo rigoroso, longo e exaustivo de passagem inicial do oral ao escrito. Para alguns pesquisadores, trata-se de operação de caráter puramente técnico, por vezes relegado a outros. No entanto, na perspectiva apresentada, a transcrição é de grande importância para a construção e análise das histórias de vida, principalmente por sua natureza reiterativa;

2. Textualização: etapa na qual as perguntas do pesquisador(a) são retiradas ou adaptadas às falas dos colaboradores. Há igualmente rearranjos a partir de indicações cronológicas e temáticas. Desse modo, busca-se facilitar a leitura do texto por meio de conformações às regras gramaticais vigentes e da supressão de partículas repetitivas, sem valor analítico, típicas do discurso oral. O objetivo é o de possibilitar uma melhor compreensão da narrativa;

3. Transcriação: refere-se a incorpração de elementos extra-textos na composição das narrativas dos colaboradores. Procura-se recriar o contexto da entrevista no documento escrito. Mais do que uma tradução, tenta-se elaborar uma síntese do sentido percebido pelo(a) pesquisador(a) além da narrativa e performance do colaborador(a). (MEIHY, 2013, p. 35). 
Durante a entrevista, a gravação é um processo de confiança e que retrata o que realmente foi dito, transparecendo marcas de humor, incertezas, dialetos. Deste modo, a gravação é diferente do registro escrito, pois o registro escrito não transparece estas marcas.

\section{AS TRANSCRIÇÕES: PARTE IMPORTANTE DA PESQUISA}

É importante explicitarmos o momento vivenciado para a realização das transcrições e o seu significado para o pesquisador. Ele representa um momento único, carregado de concepções, valores, anseios e frustrações.

Ao final das entrevistas, é possível descobrir várias questões; dentre elas, que a transcrição de uma entrevista não é apenas a transcrição fria, pois é um documento e, por isso, tem um significado social, revela os papéis sociais desempenhados pelos indivíduos na sociedade, o que se expressa na fala dos sujeitos entrevistados, por meio de suas memórias, como salientam Bueno, Catani e Souza (1998):

[...] a memória é marcada e estruturada pelos tipos de papéis sociais desempenhados, diversificando-se constituem no confronto de muitas variáveis, tais como o meio social, o nível de estudos, a participação política, a faixa etária, as quais por sua vez interferem na recuperação do passado. (BUENO; CATANI; SOUZA, 1998, p. 46).

Sendo assim, quem transcreve uma narrativa tem a responsabilidade de preservar o que foi dito. Logo vimos, ao iniciar o trabalho, que, para alguns entrevistadores, o objeto da pesquisa estava mais claro que para outros, daí algumas entrevistas ficarem mais coerentes com o tema e o objetivo da pesquisa e fornecerem mais elementos para análise.

Constatamos que um entrevistador, para fazer seu trabalho de campo, deve compreender qual é o problema que desencadeou a pesquisa, bem como os objetivos que a norteiam. Dessa forma, seu trabalho será direcionado, o que possibilitará atingir os fins propostos. Durante a entrevista e a transcrição, devemos ter clara a concepção da metodologia da História Oral, pois a falta de objetividade sobre a pesquisa e a metodologia pode reduzir a entrevista a uma técnica.

Como ouvintes de diversas entrevistas, percebemos alguns pontos a serem repensados para a sua realização. Concordamos com Thompson (1998), quando afirma que quando as perguntas são evasivas, as respostas, em decorrência, fogem do questionamento.

Para a transcrição das entrevistas, é importante saber usar a pontuação e, numa ou noutra grafia fonética, transmitir a natureza da fala. Thompson (1998) defende a transcrição integral das fitas. O gaguejar em procura de uma palavra pode ser eliminado, mas outros tipos de hesitações e de "muletas", como "você sabe" ou "veja bem", devem ser incluídos. A variedade 
linguística própria do meio sociocultural do entrevistado, da qual faz uso, deve ser respeitada. Caso durante a transcrição não se consiga compreender uma palavra ou uma frase, deve ser deixado um espaço marcado por parênteses com reticências como indicação (THOMPSON, 1998).

Acreditamos que retirar alguns vícios de linguagem pode maquiar a imagem da entrevista, mas a não retirada desses vícios, muitas vezes, impede que os entrevistados autorizem a utilização de seus relatos, pois os consideram como erros de linguagem que empobrecem sua história narrada. As marcas linguísticas utilizadas pelo narrador imprimem, no documento transcrito, um caráter identitário do indivíduo e do seu grupo social de pertencimento. Essas dimensões inerentes às entrevistas são salientadas também, pois "as narrativas são utilizadas acima de tudo para caracterizar as comunidades e os indivíduos e para transmitir suas atitudes" (THOMPSON, 1998, p. 185).

As entrevistas são carregadas de concepções, representações e valores dos sujeitos envolvidos. Primeiro, vêm as do pesquisador, e em seguida, as do narrador. Ao transcrevê-las descobrimos também que existem as concepções, representações e valores tanto de quem as ouve quanto de quem as transcreve. Defendemos que as transcrições das gravações devem ser feitas pelo próprio pesquisador, uma vez que ele tem mais possibilidades de compreender, de perceber os sentidos das falas, já que presenciou as reações do narrador e pôde anotar, em um caderno, o que vivenciou durante a entrevista.

Compreender a metodologia da História Oral é de suma importância para a sua utilização nas pesquisas em educação. Precisamos entender a diferença entre esta metodologia e a técnica de entrevistar pessoas. Para investigar a história da alfabetização a partir das práticas das alfabetizadoras, a História Oral nos permite trazer à tona questões que não estão expostas nos documentos oficiais.

Para a coleta de dados, as entrevistas orais temáticas ${ }^{2}$, cujas narrativas alargam, de forma significativa, a perspectiva da pesquisa, contribuem para a construção da História da Alfabetização. Nesse sentido, reafirmamos que uma das grandes vantagens da utilização de depoimentos orais está na possibilidade de também poder proporcionar à escrita da história a incorporação de atores e vozes que possivelmente seriam esquecidos, perdendo-se para sempre.

\footnotetext{
${ }^{2}$ No trabalho utilizamos um roteiro semi-estruturado a partir da temática prática nas salas de alfabetização. O roteiro de entrevista utilizado está disponível na pesquisa "História de alfabetizadoras Uberlandenses: modos de fazer no Grupo Escolar Bom Jesus 1955 a 1971”, disponível em https://repositorio.ufu.br/handle/123456789/13857.
} 
As pesquisas sobre alfabetização, por um longo período, se focalizaram nos métodos de alfabetização. Há uma escassez de documentos sobre a sua prática e constituição. Dessa forma, as vozes de quem participou desse processo, professor ou aluno, enriquecem, de forma considerável, as pesquisas que buscam constituir a história da alfabetização no Brasil.

\section{A CARTILHA E SUAS IMPLICAÇÕES}

Dentro dessa nova ótica historiográfica, inicio meu trabalho pesquisando as práticas e métodos pedagógicos dos impressos escolares utilizados no grupo escolar Bom Jesus, mais especificamente as práticas de leitura e escrita oriundas destes impressos escolares ${ }^{3}$ utilizados no período de 1961 a 1971, observando que a história é a "Ciência dos Homens" "dos Homens, no tempo", como afirma Bloch (2002).

Portanto, com o desenvolvimento da escolarização das práticas de leitura e escrita, a cartilha consolida-se como um imprescindível instrumento de concretização dos métodos propostos e, em decorrência, de configuração de determinado conteúdo de ensino, assim como de certas silenciosas, mas operantes, concepções de alfabetização, leitura, escrita e texto. Nesse sentido, utilizamos como aporte teórico a História Cultural, a qual propõem uma nova forma de interrogar a realidade tomando como base temas do domínio da cultura e salienta o papel das representações.

Destarte, as alfabetizadoras brasileiras tomaram ao longo dos anos como base uma imagem idealizada de linguagem e da língua. A cartilha foi aos poucos substituindo o processo de estudos e planejamento das alfabetizadoras, na medida em que traz no seu bojo métodos e conteúdos de ensino previamente estabelecidos pelos autores.

A cartilha, como instrumento de alfabetização, instituiu e perpetuou as crenças da elite mineira que, embora aparentemente restrito aos limites da sala de aula, tende a silenciosamente acompanhar esses sujeitos em outras esferas de sua vida pessoal e social, uma vez que:

\footnotetext{
Se o imperativo da "transposição didática" impõe a emergência de configurações cognitivas específicas (os saberes e os modos de pensamento tipicamente escolares), estas configurações tendem a escapar de seu estatuto puramente funcional de instrumentos pedagógicos e de auxiliares das aprendizagens, para se constituir numa espécie de "cultura escolar", dotada de dinâmica própria e capaz de sair dos limites da escola para imprimir sua marca "didática" e "acadêmica" a toda espécie de outras atividades [...], sustentando assim com as outras dinâmicas culturais relações complexas e sempre sobre determinadas, de nenhum modo redutíveis, em todo caso, aos processos de simples reflexo ou de "repartição de tarefas" [...]. (FORQUIN, 1993, p. 17-18).
}

\footnotetext{
${ }^{3}$ Considerando apenas as Cartilhas dentre todos os impressos escolares possíveis de ser encontrados.
} 
No que se refere à história da alfabetização no Brasil, as cartilhas são ícones importantes, mesmo tendo passado por variações. Certos aspectos tidos como universais e constitutivos da cultura escolar brasileira prevaleceram, para cujo engendramento, transmissão e perpetuação, têm-se, aliado o conservadorismo cultural da escola às práticas das alfabetizadoras, que apoiaram seus trabalhos fundamentalmente nas cartilhas e nos seus métodos de alfabetização. Como afirma Chartier (1990):

As representações do mundo social assim construídas, embora aspirem à universalidade de um diagnóstico fundado na razão, são sempre determinadas pelos interesses de grupo que as forjam. Daí, para cada cãs, o necessário relacionamento dos discursos proferidos com a posição de quem utiliza. (CHARTIER, 1990, p.17).

Desta forma, um dos principais aspectos da cultura que se constitui objeto de ensino na escola é precisamente a linguagem/língua, que nos precede, ultrapassa, institui e constitui como seres humanos e sujeitos sócio-históricos. Daí, decorre a importância deste estudo que tem a intenção de investigar quais foram as práticas de leitura e escrita oriundas da das cartilhas utilizadas no Grupo Escolar Bom Jesus, bem como a representação das alfabetizadoras sobre as experiências vivenciadas com a referida cartilha.

Os primeiros livros de alfabetização, sobretudo as cartilhas, são representativos das práticas e ideários pedagógicos, assim como das práticas editoriais e, historicamente, vêm se constituindo como primeira via de acesso à cultura do impresso, uma vez que em nossa sociedade grandes parcelas da população vieram constituindo suas "bibliotecas" e seus modos de ler a partir da escola.

De modo geral, a Cartilha apresenta os conhecimentos obedecendo a motivações diversas e, principalmente o modo como àqueles que a conceberam acreditam que deve ser apresentado. Nessa perspectiva, buscaremos identificar a estrutura das cartilhas utilizadas no período, sua organização interna, suas variações, distribuição e a disposição espacial dos diversos elementos textuais ou icônicos no interior de suas páginas, além do método trabalhado por ela, auxiliando assim a construir a história da alfabetização no período de 1961 a 1971 e desvendando o que este impresso representou para as alfabetizadoras e quais as concepções de criança, método, sociedade, cultura, leitura e escrita que a autora da cartilha concebeu. É necessário verificar quais foram os usos, os manuseios e as formas de apropriação e de leitura destas cartilhas pelas alfabetizadoras. “A orientação teórica presente atualmente defende que o processo de construção de interpretações sobre o passado se faz no diálogo necessário entre nossas ideias e concepções e os indícios que conseguimos agrupar para corroborar nossas assertivas" (GATTI JÚNIOR, 2002, p. 29). 
Uma proposta de investigação dessa natureza deve ser realizada com base em textos impressos, arquivados ao longo dos anos e, na memória daqueles personagens que participaram da história da alfabetização em Uberlândia. Como afirma Chartier (1990), nas representações a percepção do social não é um discurso neutro, nela está embutida a vivência dos indivíduos, suas escolhas e condutas, suas práticas, concepção de mundo, valores, motivos, significados, atitudes, suas representações sobre determinada realidade, seja ela política, escolar, econômica, religiosa, social etc.

Tendo em vista que a prática escolar é influenciada por fatores externos como políticas educacionais, diretrizes pedagógicas entre outros e internos, expresso nas representações veiculadas pelos valores, motivos, comportamentos etc, podemos afirmar que quem escreveu as "Cartilhas" tinha um ideário, a escreveu com um intuito que nem sempre se cumpriu ao ser trabalhada pelos professores, já que não escrevemos livros, mas sim textos que a editora transforma em livro. O autor não controla o sentido, pois após a publicação os textos se tornam público, afirma Chartier (2002).

Nesse contexto tentaremos reconstruir os saberes e as práticas das alfabetizadoras. Para isso, utilizaremos todas as fontes possíveis, já que a Nova História privilegia a documentação massiva e involuntária em relação aos documentos voluntários e oficiais: arqueológicos, pictográficos, iconográficos, fotográficos, cinematográficos, numéricos e orais. Todos os meios são tentados para vencer as lacunas e silêncios das fontes, mesmo, e não sem risco, os considerados como antiobjetivos.

Nesta perspectiva trabalhamos com as fontes documentais e fontes orais. Buscamos na voz das professoras a história da alfabetização em Uberlândia, já que esta é uma importante forma de caracterizar e perpetuar as tradições culturais. A história oral esta presente em nossas vidas e tem grande importância para a pesquisa, na medida em que revela os fatos pessoais que em sua maioria não foram documentados.

\section{RESULTADOS E DISCUSSÃO}

Para o desenvolvimento deste estudo, foi de suma importância o acesso ao material utilizado pelas alfabetizadoras. Como na escola Bom Jesus encontramos somente algumas fotos do período pesquisado, foi necessário encontrarmos as cartilhas e o Programa de Ensino. A partir desta constatação, iniciamos uma busca nos sebos para encontrar as cartilhas utilizadas no período em estudo. Assim, conseguimos encontrar vários exemplares de cartilhas e manuais do professor das décadas de 60 e 70 . Iniciamos nossa biblioteca pessoal de cartilhas antigas. 
Para as entrevistas, este material foi precioso, pois auxiliou as alfabetizadoras que, ao verem os livros que utilizaram, lembravam-se de mais detalhes e reviveram aquele momento que eram alfabetizadoras no Grupo Escolar Bom Jesus.

O nosso propósito com este estudo foi compreender quais eram as práticas das alfabetizadoras do Grupo Escolar Bom Jesus de 1955 a 1971, a fim de contribuir para a construção da história da alfabetização no município de Uberlândia. À medida que nos aproximamos do nosso objeto de estudo, crescia uma inquietude que se traduziu na busca de entender quais as representações dessas alfabetizadoras e como se deram suas práticas.

Nesse sentido, a partir das narrativas de cinco alfabetizadoras que são as testemunhas do período pesquisado, dos documentos encontrados e das referências sobre o assunto, tentamos tecer a trama que se processou em torno delas, quanto às práticas de alfabetização.

Assim, na construção deste trabalho, identificamos algumas questões relevantes das práticas das alfabetizadoras e, para entendermos tais práticas, a história do Grupo Escolar Bom Jesus foi importante, à medida que explicita os ideais representados naquele Grupo, baseados no lema "ordem e progresso" os quais corporificaram os símbolos e valores da pedagogia moral e cívica. Apesar de a criação do Grupo Escolar Bom Jesus ter acontecido apenas em 1955, ele ainda reproduzia as propostas dos primeiros grupos escolares que eram: educar no sentido de civilizar, moralizar e higienizar os seus alunos. A escola representava com afinco os ideais da República Brasileira.

Entender a história político-educacional no Brasil durante os anos de 1955 a 1971 auxiliou na análise das práticas das alfabetizadoras, pois as práticas não são isoladas e externas à sociedade, mas sim representações de cada alfabetizadora sobre a sua realidade dentro da sociedade. Dessa forma, contextualizamos o cenário político-educacional brasileiro, a partir da década de 20, a fim de identificarmos as concepções que permearam a elaboração e promulgação da Lei Orgânica do Ensino Primário - Decreto Lei no 8.529. Assim, percorremos este cenário até o ano de 1971, ano da promulgação da Lei de Diretrizes e Bases de Educação Nacional $n^{\circ}$ 5.692, sendo que esta lei extinguiu a denominação Grupo Escolar e modificou a estrutura educacional. Neste sentido, escolhemos o ano de 1971 para encerrar este estudo, pois marca uma nova política educacional.

Durante o período em estudo, identificamos algumas políticas de produção do livro didático, porém não havia programas de distribuição deste material, assim o governo não distribuía cartilhas nos Grupos Escolares e, apesar de o Decreto-Lei no 8460 de 1945 determinar que a escolha do livro didático deveria ser função do professor, isso não acontecia no Grupo Escolar Bom Jesus. Segundo as alfabetizadoras Aguiar, Bezerra, Zacarias e Mancini, os livros 
didáticos eram escolhidos pela direção da escola. Quando perguntada sobre a quem escolhia os livros didáticos, Aguiar respondeu: "Com certeza, a diretora. O professor não interferia na escolha. Quando começavam as aulas, a cartilha já estava adotada.” (AGUIAR, 2010).

De acordo com os documentos encontrados e com as leis vigentes no período em estudo, a primeira dedução que tivemos foi a de que, no período de 1955 a 1971, dentro do Grupo Escolar Bom Jesus, o processo de alfabetização infantil seguia os moldes ditados pelo Programa de Ensino Primário Elementar de Minas Gerais.

A partir da formação dessas alfabetizadoras, poderíamos acreditar que todas trabalharam o método Global, já que o mesmo foi difundido com ênfase durante o período em que as elas cursaram o Normal. Porém, ao analisarmos suas práticas, a partir das entrevistas realizadas, identificamos que se pregava a utilização do método Global, mas poucas alfabetizadoras realmente conseguiam alfabetizar com tal método.

Os manuais das cartilhas O livro de Lili e As Mais Belas Histórias apresentavam o verdadeiro tratado sobre o método Global, discorrendo sobre todas as etapas e procedimentos para implementação desse sistema. Tais procedimentos também eram comuns ao Programa de Ensino. Como os três materiais seguiam as ideias de Lucia Casasanta, já que dois foram escritos por ela e O livro de Lili por uma aluna sua, esses materiais defendiam o Método Global e ensinavam a alfabetizadora a trabalhar com ele.

Todos os indícios encontrados nos levavam a acreditar que o método global teria sido utilizado em sua totalidade no Grupo Escolar Bom Jesus por todas as alfabetizadoras, porém nas suas narrativas identificamos que, na prática, elas utilizavam o método silábico ou alfabético. Segundo Mancini, havia um período preparatório antes de iniciar o método global.

\footnotetext{
Ah, mas a hora que você chegava com este pré-livro eu já tinha trabalhado tudo isto aqui. Porque primeiro, no período preparatório, eu começava com as vogais e o alfabeto. Nós chamávamos esse período de preparatório. Período preparatório que fazíamos depois adotávamos a cartilha. Porque as crianças já conheciam as vogais já sabiam as sílabas. Assim, para trabalhar uma lição desta era quase que três a quatro dias. Até a criança aprender. (MANCINI, 2010).
}

Assim, as entrevistadas afirmaram que alfabetizavam com os pré-livros (cartilhas do método global), porém todas admitiram que quando o aluno não conseguia aprender pelo método global, elas trabalhavam com o método silábico ou alfabético.

Além disso, duas alfabetizadoras disseram que antes de começar a trabalhar com o prélivro, sempre faziam uma preparação do alfabetizando. Essa preparação consistia em ensinar para os alunos as vogais, consoantes e as sílabas. Dessa forma, quando iniciavam o pré-livro, a criança já reconhecia as sílabas e conseguiriam aprender a ler fluentemente. 
As outras alfabetizadoras narram também sobre o período preparatório, exemplificaram o que elas faziam nessa etapa da alfabetização:

Eu tenho um caderno aí que era do período preparatório que eu achava muito bom. Nas escolas, numa época, primeiro a gente dava o período preparatório que era como se fosse... deveria ser usado hoje no pré, e agora já tem o primeiro ano introdutório. Eu guardei com muito carinho porque a gente tinha um programa do Estado. Eu tenho um caderninho se você quiser, eu te mostro. Olhe: correspondência - fazer correspondência de um desenho ao outro, traçar por cima do pontilhado, vários tipos dessas atividades, até mesmo com gravuras ou a gente fazia a mão a gente fazia um joguinho para cada aluno. (PAFUME, 2010).

Apesar de relatar que seguiam a sequência do Programa de Ensino, as atividades descritas pelas alfabetizadoras são características do método sintético. Apenas as alfabetizadoras Bezerra e Mancini narraram explicitamente a preparação como o método sintético, para depois trabalhar com o analítico

Podemos elucidar que o grupo escolar seguiu as orientações do governo mineiro, porém dentro da sala de aula, cada alfabetizadora deu o seu significado ao programa, sempre tendo algumas questões comuns a toda a escola. Como por exemplo, o ensino de ciências, o estímulo à leitura e à higiene dos alunos. Como afirma Mancini (2010):

Tínhamos que tirar os piolhos. Lá, nós dávamos banho tirávamos os piolhos passávamos remédio na cabecinha, fazíamos tudo. Éramos mãe na parte de higiene. Mas como a escola era central, tinha muitos alunos filhos de famílias abastadas, mas tinha os pobres também.

Destarte, ao se tratar das questões metodológicas da alfabetização, identificamos que os documentos são diferentes das práticas. As alfabetizadoras sempre afirmavam o que o Programa de Ensino determinava, mas quando relataram como eram suas aulas, elucidamos que o método utilizado para alfabetizar os alunos foi o tradicional, silábico ou alfabético.

Por isso, por todo o período deste estudo sempre se utilizaram duas cartilhas: uma do método Global e outra do método silábico ou alfabético. A cartilha Caminho Suave, que consideramos do método sintético, esteve presente por todo o período em estudo, sendo utilizada para alfabetizar aqueles alunos que não conseguiam acompanhar o método Global.

Podemos inferir que, ao longo desses 16 anos pesquisados, o método Global, na forma idealizada por Lúcia Casasanta e pelo Programa de Ensino Primário Elementar, não foi trabalhado nesse Grupo Escolar, pois ele sempre foi acompanhado do período preparatório, no qual as alfabetizadoras ensinavam as sílabas para que, ao entrar no pré-livro, as crianças não ficassem com tamanhas dificuldades de acompanhamento em sala de aula. Dessa forma, o pré- 
livro funcionava como o livro de leitura, no qual a criança iria treinar e melhorar a sua leitura, interpretação e vocabulário.

$\mathrm{Na}$ concepção das alfabetizadoras, no período de alfabetização, todos os alunos deveriam ler com fluência, sem soletrar as palavras e ainda escrever corretamente. Dessa forma, a criança que terminava a primeira série do ensino primário deveria escrever e ler corretamente. Assim, era cobrado de todos os alfabetizandos uma grafia correta com a supervisão da diretora ou da vice-diretora. Ademais, era tomada a leitura, pois se o aluno não lesse e escrevesse corretamente ele não poderia passar para a segunda série do ensino primário.

\section{CONSIDERAÇÕES FINAIS}

Os resultados desse estudo mostram que as alfabetizadoras do Grupo Escolar Bom Jesus dedicaram-se ao processo de alfabetização, empenharam-se em ensinar a ler, escrever e valorizar os procedimentos básicos de higiene pessoal, bem como divulgaram a moral e o civismo. Este estudo alargou nossos conhecimentos sobre a história da alfabetização. Fizemos algumas considerações deste estudo, porém não iremos concluir, pois esta pesquisa provocou outras inquietudes a respeito da história da alfabetização: Quais foram as representações das alfabetizadoras de outros períodos e de outros Grupos Escolares? E como foi difundido e aprendido o método Global nas escolas Normais? Ficam aqui inquietudes que poderão culminar em outras pesquisas.

\section{REFERÊNCIAS}

AGUIAR, M. A. Entrevista cedida à pesquisa História de alfabetizadoras uberlandenses: modos de fazer no Grupo Escolar Bom Jesus - 1955 a 1971, em 2010.

BLOCH, Marc. Apologia da História ou o ofício de Historiador. Trad. André Telles. Rio de Janeiro: Jorge Zahar, 2002.

BOURDÉ, Guy; MARTIN, Hervé. As escolas históricas. São Paulo: Publicações EuropaAmérica, 2018.

BRASIL. Decreto-Lei no 8.530, de 2 de janeiro de 1946. Lei Orgânica do Ensino Normal. Disponível em: <http://www2.camara.leg.br/legin/fed/declei/1940-1949/decreto-lei-8530-2janeiro-1946-458443-publicacaooriginal-1-pe.html>. Acesso em: 26 nov. 2015.

Lei $n^{0}$ 5.692, de 11 de agosto de 1971. Coleção de Leis do Brasil. p. 59, v. 5. 
Disponível em: <http://www2.camara.leg.br/legin/fed/lei/1970-1979/lei-5692-11-agosto1971-357752-publicacaooriginal-1-pl.html>. Acesso em: 26 nov. 2015.

BUENO, Belmira Oliveira; CATANI, Denice Barbara; SOUSA, Cynthia Pereira de. (Org.). A vida e o ofício dos professores. São Paulo: Escrituras, 1998.

CHARTIER, Roger. A História Cultural: entre práticas e representações. 2. ed. Portugal: DIFEL, 1990.

. Os desafios da escrita. Tradução de Fúlvia M. L. Moretto. São Paulo: UNESP, 2002.

DELGADO, Lucilia de Almeida Neves. História oral: memória, tempo, identidade. Belo Horizonte: Autêntica, 2006.

FORQUIN, Jean-Claude. Escola e cultura: As bases sociais e epistemológicas do conhecimento escolar. Trad. Guacira Lopes Louro. Porto Alegre: Artes Médicas, 1993.

GATTI JÚNIOR, Décio. Apontamento sobre a pesquisa histórico-educacional no campo das instituições escolares. Cadernos de História da Educação, v. 1. n. 1, jan./dez. 2002.

GINZBURG, Carlo. Mitos, Emblemas e Sinais: morfologia e história. São Paulo: Cia das Letras, 1989.

HALBWACHS, Maurice. A memória coletiva. Tradução de Beatriz Sidou. São Paulo: Centauro, 2006.

JULIA, Dominique. A cultura escolar como objeto histórico. Trad. Gisele de Souza. Revista Brasileira de História da Educação, SBHE. Campinas, SP: Autores Associados, n. 1, p. 0943, jan./jun. 2001.

MANCINI, S. A. Entrevista cedida à pesquisa História de alfabetizadoras uberlandenses: modos de fazer no Grupo Escolar Bom Jesus - 1955 a 1971, em 2010.

MEIHY, José Carlos Sebe Bom. Manual de História Oral. São Paulo: Loyola, 2013.

; HOLANDA, Fabíola. História oral: como fazer, como pensar. São Paulo: Contexto, 2007.

NORA, Pierre. Entre Memória e História: a problemática dos lugares trad. Yara Aun Khoury. Projeto História: Revista do Programa de Estudos de Pós-Graduação em História e do Departamento de História da PUC-SP. São Paulo, SP, n. 10, p. 7-28, dez. 1981.

PAFUME, S. Entrevista cedida à pesquisa História de alfabetizadoras uberlandenses: 
modos de fazer no Grupo Escolar Bom Jesus - 1955 a 1971, em 2010.

PESAVENTO, Sandra Jatahy. A História e História Cultural. Belo Horizonte, MG: Autêntica, 2012.

THOMPSON, Paul. A voz do passado, história oral. São Paulo: Paz e Terra, 1998. 